\title{
The Relationship Between Nursing Students' Attitudes Toward the Nursing Profession Concerning Career Choice and Motivation
}

\author{
(D) Derya Suluhan ${ }^{1}$, (1) Elif Gezginci2 , (1) Merve Esra Ergin ${ }^{3}$ \\ 1 University of Health Sciences Turkey, Gülhane Faculty of Nursing, Department of Pediatric Nursing, Ankara, Turkey \\ 2 University of Health Sciences Turkey, Hamidiye Faculty of Nursing, Department of Surgical Nursing, Istanbul, Turkey \\ ${ }_{3}^{3}$ Çorlu State Hospital, Department of Pediatric, Tekirdağ, Turkey
}

\section{Abstract}

Objective: Nursing students must voluntarily choose the nursing profession and be motivated to have a positive attitude toward the profession. The study aimed to evaluate the relationship between nursing students' attitudes toward their profession and their career choice and motivations.

Methods: The study included 302 nursing students studying at a state university in Turkey between December 2018 and January 2019. The data were collected using the data collection form, attitude scale for nursing profession, the scale of nurse career choice, motivation sources, and problems scale. Descriptive statistics, independent t-test, Mann-Whitney U test, One-Way analysis of variance test, Kruskal-Wallis test, and Pearson's and Spearman's correlation coefficients were used for data analysis.

Results: The mean age of the participants was $21.1 \pm 1.6$ years, and $87.4 \%$ of them were women. A statistically significant difference was found among the class levels and attitudes toward the nursing profession, properties of nursing profession, prefer for nursing profession, nurse career choice, occupational compliance, vital causes, and negative motivation $(p<0.05)$. A statistically significant difference was found between gender and attitudes toward the nursing profession, properties of nursing profession, prefer for nursing profession, general position of nursing profession, occupational compliance, motivation, intrinsic motivation, extrinsic motivation, and negative motivation $(p<0.05)$. A statistically significant positive correlation was found between attitudes toward the nursing profession and the following factors: nurse career choice, occupational compliance, motivation, intrinsic motivation, extrinsic motivation, and negative motivation $(\mathrm{p}<0.05)$.

Conclusion: According to this study, it was concluded that nurse career choice and motivation positively affected nursing students' attitudes toward the nursing profession.

Keywords: Attitude, career choice, motivation, nursing, nursing student

\section{INTRODUCTION}

Nursing remains a common career choice for both younger and older students entering university. The choice of the nursing profession may be related to internal factors (such as liking the profession, having a partner in the healthcare field, being kept apprised of the nursing profession, and having the desire to help others or a general affection for people) or external factors (such as job guarantee, family desires or pressure, and exam scores)
(1). One study in regional Australia found that the main reasons students enrolled into nursing programs were altruism, vocation, and interest, and they consider nursing to be a career that one can easily progress up the promotion ladder (2).

The motivation for students' choosing nursing is related to both internal and external factors including being admitted to the first choice program, choosing a field according to personal interests, opening opportunities for career progression, making a 
career in nursing, having nursing/caring experience, and having a desire to help others (3). In a study by Jirwe and Rudman (3), approximately $75 \%$ of the respondents wanted to care for and help others. Problems of the nursing profession such as educational differences, financial situations, traditional values and culture, gender differences, work environment, and media's depiction of nurses have negative effects on the motivations of nursing students. Existing literature demonstrates a poor perception of nurses from the public through media misperception $(4,5)$. Participants in the study by Liu expressed that they would not encourage their children, especially their sons, to become nurses according to traditional norms and values (5).

The attitudes of professionals working within a given field are important to achieving professional status and providing qualified service to the society. The attitude of the individual toward a profession affects his or her success and satisfaction within the profession (5). To make an accurate and appropriate career choice decision, the person should know what he or she wants, know what he or she can do, and have positive attitudes toward that profession. A study by Al Jarrah (6) revealed that nursing students' attitudes toward the profession are positive. A study by Čukljek et al. (7) also found that nursing students had positive attitudes toward nursing in their first and third years of study, and a positive change in attitudes was influenced by the acquisition of knowledge and skills.

Although there are a limited number of studies examining the attitudes of nursing students regarding the profession and factors that lead them to select the profession, no study has evaluated the relationship between the attitudes toward the profession, factors of profession selection, and sources of motivation using valid and reliable scales $(8,9)$. Thus, this study aimed to determine the relationship between nursing students' attitudes toward the nursing profession concerning career choice and motivation.

\section{METHODS}

\section{Study Design}

This study was a descriptive, cross-sectional study.

\section{Settings and Participants}

The study population included 474 nursing students from a state university between December 2018 and January 2019 in Ankara, Turkey (class I: 174, class II: 168, and class IV: 132 students). There was no sample exclusion process, and the total population was invited to participate. Of the nursing students, only 302 met the following inclusion criteria: being a nursing student and willing to participate in the study. Class III was excluded in the study because there were no students enrolled. Nursing students were not admitted to Gülhane Nursing Faculty in the academic year September 2016 because of the July 15, 2016, coup attempt in Turkey. Thus, there were only first-, second-, and fourth-year nursing students at the beginning of the study in 2018.

\section{Data Collection Tools}

Data Collection Form: The data collection form was created by the researchers after completing the literature review. The form consisted of 10 questions about demographic data, reasons for choosing the profession, attitudes toward the profession, and future planning related to the profession.

Attitude Scale for Nursing Profession (ASNP): The scale was developed in 2010 by Coban and Kasikci (10) to evaluate attitudes toward the nursing profession. It uses a five-point Likert-type scale and contains 40 items. It consists of three dimensions: properties of nursing profession (items 1-18), prefer for nursing profession (items 19-31), and general position of nursing profession (items 32-40). Each item in the scale was scored from 1 to 5 , but items $21,23,25,26,28,30,34$, and 38 were scored in reverse. A high score indicates that attitudes toward the nursing profession are more favorable. The Cronbach's $\alpha$ value for the total scale was 0.91 . In our study, the Cronbach's $\alpha$ value for the total scale was 0.90

The Scale of Nursing Career Choice (SNCC): This scale was developed by Zysberg and Berry (11) to assess reasons for the career choices of nursing students. Onler and Saracoglu (12) conducted the Turkish validity and reliability study of the scale. The Turkish version of the scale consists of 17 items and 2 subdimensions, namely, occupational compliance (1) and vital causes (6). Each item in the Likert-type scale was rated between $0 \%$ and $100 \%$. Since the scale is not used for diagnostic purposes, the obtained score ranges were interpreted. The Cronbach's $\alpha$ value for the total scale was 0.79 . In our study, the Cronbach's $\alpha$ value for the total scale was 0.85 .

Motivation Sources and Problems Scale (MSPS): The scale was developed by Acat and Kosgeroglu (13) to determine the motivation sources and problems of nursing students. The scale comprises 24 items and 3 subdimensions including intrinsic motivation (1), extrinsic motivation (13), and negative motivation (5). The scale is a five-point Likert type, and the items in the negative motivation subdimension are scored in reverse order. The score of each subdimension is determined by taking the arithmetic average of the scores obtained from the items of the subscale. A high score indicates a high level of motivation. The 
minimum and maximum scores are 11 and 55 for the intrinsic motivation subdimension, 5 and 25 for the extrinsic motivation subdimension, and 8 and 40 for the negative motivation subdimension, respectively. The Cronbach's $\alpha$ value for the total scale was 0.82 . In our study, the Cronbach's $\alpha$ value for the total scale was 0.88 .

\section{Data Collection}

Data were obtained using a face-to-face interview method. The interviews lasted approximately 20-25 min.

\section{Statistical Analysis}

Statistical analysis was done using the SPSS 22 package program. Number, percentage, minimum, maximum, median, mean, and standard deviation values were used for descriptive analysis. Normal distribution was evaluated using the KolmogorovSmirnov test. The independent $\mathrm{t}$ and Mann-Whitney $\mathrm{U}$ tests were used to compare two groups with normal and non-normal distributions, respectively. Meanwhile, One-Way analysis of variance and Kruskal-Wallis tests were used to compare three and more groups with normal and non-normal distributions, respectively. The strength and relationship direction between two variables were determined using the Pearson's and Spearman's correlation coefficients. A value of $p<0.05$ was considered to be statistically significant.

\section{Ethical Considerations}

The authors declare that the research was conducted according to the principles of the World Medical Association Declaration of Helsinki "Ethical Principles for Medical Research Involving Human Subjects" (amended in October 2013). Ethical approval was obtained from the Non-Interventional Clinical Research Ethics Board of the University Health Sciences Turkey (18/322). Authors' permissions were obtained for the use of the scales. After the participants were informed about the study, data were collected from those who agreed to participate. The study was conducted on a voluntary basis.

\section{RESULTS}

Table 1 shows the descriptive characteristics of the participants. The mean age of the participants was $21.1 \pm 1.6$ years, and $87.4 \%$ of them were women. Primarily, $55.9 \%$ of participants chose nursing because of the guarantee of employing with respect to career choice. Of the participants' mothers, $48 \%$ graduated from primary school, and $37.1 \%$ of the fathers graduated from high school. More than half (63.2\%) of the participants had a monthly family income status of equal to the outcome.
Table 2 shows the comparison of the difference between class levels of participants and attitudes toward the nursing profession, career choice, motivation sources, and problems. A statistically significant difference among class levels was noted on the following items: attitudes toward the nursing profession, properties of nursing profession, prefer for nursing profession, nurse career choice, occupational compliance, and vital causes $(p<0.05)$. A statistically significant difference among class levels was found in the negative motivation subdimension of the MSPS.

Table 3 shows the comparison of gender differences across attitudes toward the nursing profession, nurse career choice, motivation sources, and problems. A statistically significant difference was found between genders in attitudes toward the

Table 1. Distribution of the descriptive characteristics of the participants $(n=302)$

\begin{tabular}{|l|l|l|}
\hline \multicolumn{2}{|l|}{ n } & $\%$ \\
\hline Class levels & 118 & 39.1 \\
\hline I & 102 & 33.8 \\
\hline II & 82 & 27.1 \\
\hline IV & \multicolumn{2}{|l|}{} \\
\hline Gender & 264 & 87.4 \\
\hline Female & 38 & 12.6 \\
\hline Male & \multicolumn{2}{|l|}{} \\
\hline Reason for career choice* & 169 & 55.9 \\
\hline Guarantee of employing & 130 & 43 \\
\hline Helping others & 91 & 30.1 \\
\hline Making a career & 83 & 27.4 \\
\hline Having a health relative & \multicolumn{2}{|l|}{} \\
\hline Mother education level & 21 & 7.0 \\
\hline Literate & 146 & 48.3 \\
\hline Primary school & 35 & 11.6 \\
\hline Secondary school & 78 & 25.8 \\
\hline High school & 22 & 7.3 \\
\hline University & 14 & 4.6 \\
\hline Father education level & 74 & 24.5 \\
\hline Literate & 34 & 11.3 \\
\hline Primary school & 191 & 63.2 \\
\hline Secondary school & 77 & 25.5 \\
\hline High school & 34 & 11.3 \\
\hline University & 112 & 37.1 \\
\hline Income level & 68 & 22.5 \\
\hline Less than expense & \multicolumn{2}{|l}{} \\
\hline Equal to expense & \multicolumn{2}{|l|}{} \\
\hline More than expense & *The participants answered in multiple choices & \\
\hline
\end{tabular}


nursing profession, properties of nursing profession, prefer for nursing profession, general position of nursing profession, occupational compliance, motivation, intrinsic motivation, extrinsic motivation, and negative motivation $(p<0.05)$.

Table 4 shows the effect of participants' attitudes toward the nursing profession on nurse career choice, motivation sources, and problems. A statistically significant positive correlation was found between attitudes toward the nursing profession and nursing career choices, occupational compliance, motivation, intrinsic motivation, extrinsic motivation, and negative motivation $(p<0.05)$.

\section{DISCUSSION}

The study aimed to determine the relationship of career choice, motivation, and nursing students' attitudes toward the profession. Career choice is defined as the process where individuals choose one occupation over another in the presence of alternative options and individual preferences (14). Students' attitudes toward the nursing profession and factors such as intrinsic, extrinsic, sociodemographic, and interpersonal are the main factors affecting students' career choices (15). In our study, we found a positive correlation of students' attitudes toward the nursing profession on nurse career choice, occupational

Table 2. Comparison of the difference between attitudes toward the nursing profession, nurse career choice, motivation sources, and class level problems $(n=302)$

\begin{tabular}{|c|c|c|c|c|c|}
\hline Scales & Class I & Class II & Class IV & Statistics & $p$ value \\
\hline & Median (min-max) & Median (min-max) & Median (min-max) & & \\
\hline ASNP (mean \pm SD) & $157.6 \pm 19.1$ & $163.5 \pm 15.6$ & $159.2 \pm 16.7$ & $3.266 *$ & 0.040 \\
\hline Properties of nursing profession & $80.0(32.0-90.0)$ & $84.0(54.0-90.0)$ & $85.5(56.0-90.0)$ & $8.456^{* *}$ & 0.015 \\
\hline Prefer for nursing profession (mean \pm SD) & $46.0 \pm 8.1$ & $47.9 \pm 8.7$ & $44.1 \pm 8.8$ & $4.609 *$ & 0.011 \\
\hline General position of nursing profession & $33.0(17.0-42.0)$ & $34.0(17.0-39.0)$ & $34.5(25.0-38.0)$ & $1.624^{* *}$ & 0.444 \\
\hline $\mathrm{SNCC}($ mean $\pm \mathrm{SD})$ & $60.9 \pm 16.2$ & $57.3 \pm 16.3$ & $51.6 \pm 14.3$ & $8.345^{*}$ & $<0.001$ \\
\hline Occupational compliance & $68.6(12.7-99.1)$ & $66.3(10.0-100.0)$ & $59.1(9.1-99.1)$ & $7.004^{* *}$ & 0.030 \\
\hline Vital causes & $52.5(5.0-100.0)$ & $44.1(3.3-91.6)$ & $39.1(13.3-66.6)$ & $32.266^{* *}$ & $<0.001$ \\
\hline MSPS & $85.0(57.0-120.0)$ & $93.0(56.0-120.0)$ & $93.0(60.0-120.0)$ & $5.759 * *$ & 0.056 \\
\hline Intrinsic motivation & $41.0(15.0-55.0)$ & $42(18.0-55.0)$ & $39.5(17.0-55.0)$ & $3.266^{* *}$ & 0.195 \\
\hline Extrinsic motivation & $20.0(5.0-25.0)$ & $21.0(9.0-25.0)$ & $21.0(10.0-25.0)$ & $2.893^{* *}$ & 0.235 \\
\hline Negative motivation & $28.0(8.0-40.0)$ & $31.0(8.0-40.0)$ & $34.0(19.0-40.0)$ & $23.469 * *$ & $<0.001$ \\
\hline
\end{tabular}

*One-Way analysis of variance test, **Kruskal-Wallis test, ASNP: Attitude scale for nursing profession, SNCC: The scale of nurse career choice, MSPS: Motivation sources and problems scale, SD: Standard deviation, min: Minimum, max: Maximum

Table 3. Comparison of the difference between attitudes toward the nursing profession, nurse career choice, motivation sources, and gender level problems of participants $(n=302)$

\begin{tabular}{|c|c|c|c|c|}
\hline Scales & Female & Male & Statistics & $\mathrm{p}$ value \\
\hline & Median (min-max) & Median (min-max) & & \\
\hline $\operatorname{ASNP}($ mean \pm SD) & $162.0 \pm 16.1$ & $146.1 \pm 19.8$ & $5.472^{*}$ & $<0.001$ \\
\hline Properties of nursing profession & $84.0(32.0-90.0)$ & $72.0(38.0-90.0)$ & $-4.978^{* *}$ & $<0.001$ \\
\hline Prefer for nursing profession (mean \pm SD) & $46.5 \pm 8.5$ & $43.3 \pm 8.3$ & 2.163 & 0.031 \\
\hline General position of nursing profession & $34.0(17.0-42.0)$ & $32.0(23.0-38.0)$ & $-5.017^{* * *}$ & $<0.001$ \\
\hline SNCC (mean \pm SD) & $57.8 \pm 15.9$ & $52.9 \pm 17.1$ & 1.723 & 0.086 \\
\hline Occupational compliance & $66.3(9.1-100.0)$ & $48.6(12.7-95.4)$ & $-2.678^{* *}$ & 0.007 \\
\hline Vital causes & $45.0(3.3-100.0)$ & $46.6(3.3-100.0)$ & $-0.977^{* *}$ & 0.328 \\
\hline MSPS & $92.0(56.0-120.0)$ & $78.0(57.0-120.0)$ & $-4.332 * *$ & $<0.001$ \\
\hline Intrinsic motivation & $41.0(15.0-55.0)$ & $34.5(17.0-55.0)$ & $-2.786^{* *}$ & 0.005 \\
\hline Extrinsic motivation & $21.0(5.0-25.0)$ & $18.0(10.0-25.0)$ & $-4.005^{* *}$ & $<0.001$ \\
\hline Negative motivation & $31.0(8.0-40.0)$ & $26.0(14.0-40.0)$ & $-3.356^{* *}$ & 0.001 \\
\hline
\end{tabular}


Table 4. Comparison of the relationship between nurse career choice, motivation sources, and problems with attitudes toward the nursing profession $(n=302)$

\begin{tabular}{|c|c|c|c|c|c|c|c|c|}
\hline & & SNCC & $\begin{array}{l}\text { Occupational } \\
\text { compliance }\end{array}$ & Vital causes & MSPS & $\begin{array}{l}\text { Intrinsic } \\
\text { motivation }\end{array}$ & $\begin{array}{l}\text { Extrinsic } \\
\text { motivation }\end{array}$ & $\begin{array}{l}\text { Negative } \\
\text { motivation }\end{array}$ \\
\hline \multirow{2}{*}{ ASNP } & r & $0.420 *$ & $0.631 * *$ & $-0.096^{* *}$ & $0.730 * *$ & $0.736^{* *}$ & $0.597 * *$ & $0.239 * *$ \\
\hline & $\mathrm{p}$ & $<0.001$ & $<0.001$ & 0.097 & $<0.001$ & $<0.001$ & $<0.001$ & $<0.001$ \\
\hline \multirow{2}{*}{ Properties of nursing profession } & $r$ & $0.220 * *$ & $0.321^{* *}$ & $-0.126^{* *}$ & $0.465^{* *}$ & $0.465^{* *}$ & $0.456^{* *}$ & $0.116^{* *}$ \\
\hline & $\mathrm{p}$ & $<0.001$ & $<0.001$ & 0.029 & $<0.001$ & $<0.001$ & $<0.001$ & 0.044 \\
\hline \multirow{2}{*}{ Prefer for nursing profession } & $r$ & $0.551^{*}$ & $0.706^{* *}$ & $-0.068^{* *}$ & $0.707^{* *}$ & $0.734 * *$ & $0.493^{* *}$ & $0.245^{* *}$ \\
\hline & $\mathrm{p}$ & $<0.001$ & $<0.001$ & 0.241 & $<0.001$ & $<0.001$ & $<0.001$ & $<0.001$ \\
\hline \multirow{2}{*}{$\begin{array}{l}\text { General position of nursing } \\
\text { profession }\end{array}$} & $r$ & $0.317^{* *}$ & $0.377^{* *}$ & $-0.009 * *$ & $0.481^{* *}$ & $0.444^{* *}$ & $0.445^{* *}$ & $0.197 * *$ \\
\hline & $p$ & $<0.001$ & $<0.001$ & 0.872 & $<0.001$ & $<0.001$ & $<0.001$ & 0.001 \\
\hline
\end{tabular}

compliance, motivation, intrinsic motivation, extrinsic motivation, and negative motivation. These findings were supported by other studies $(15,16)$.

Our study revealed that first-year students were more likely to choose the nursing profession and found the profession more suitable than other classes. Similarly, studies of Grainger and Bolan (17) and Miers et al. (18) found that students have a quite positive image of nursing in their first year of education and believe in the importance of nursing research and nurses' role in policy development.

With respect to career choice, students in our study chose nursing because of the guarantee of employing, helping others, having a healthy relative, and making a career in nursing. These results also corroborate with a previous study (17). In developed and prosperous countries, although there are internal reasons such as interest, professional appeal, being a health professional, personality traits, liking people, living in developing societies, work guarantee, economy, family influence, pressure, and score, external choice seems to be more effective (18). The internal reasons are preferable in Turkey, whereas external causes influenced some Asian and European countries predominantly (19).

In our study, it was determined that fourth-year nursing students who had experienced applied clinical practice were negatively motivated toward the profession. This occurs as they share their clinical experience with nurses who have a high patient number, heavy workload, long shift, and uncertain role experience and have used complex tools and equipment (20).

The positive progress of the training process will help nursing students to better adapt to their future professional life and find satisfaction in their professions (21). In our study, positive attitudes toward the characteristics of the nursing profession are higher in nursing students in their last year. Changes in students' perceptions as they progress through the nursing program have been noted in literature. Sand-Jecklin and Schaffer (22) found that $95 \%$ of students reported that their perceptions had changed over time. Turgay et al. (23) also stated that most of the nursing students had negative opinions against nursing before starting school and that these thoughts increased positively and partially during the education process.

Gender stereotyping of profession is still evident today. It is thought that professions such as teaching and nursing, which employ the assumed caring and subtle character of women, are viewed suitable for women by many societies (24). In our study, it was determined that gender affected attitudes toward profession and positively affected attitudes toward profession, attitudes toward the characteristics of profession, and preference for profession. These results are largely similar to the studies conducted in other countries (25). The study shows that men continue to encounter much prejudice and many social barriers when they go into the nursing profession.

In our study, a positive attitude toward the profession is mostly found in first-year students. It is largely similar to studies conducted in other countries (26). A cross-sectional study conducted on 132 nurses in Israel reported that nurses perceived their profession positively (27). In another study, the perceptions of 100 nursing students were found to be positive in Jordan (6). In our study, students who were new to nursing education relate their perspective of nursing to the school. It is important to show that the attitudes of the Turkish society toward the nursing profession have changed positively. 
Choosing a profession is an important decision in an individual's life, and many factors affect the individual in this decision process. A positive attitude toward the profession is an important factor affecting the choice of profession. In our study, a positive relationship was found between attitudes toward the nursing profession and the choice of profession. No study was found to determine the relationship between ASNP and SNCC by using valid tools. In the studies of Guducu Tufekci and Yildiz (28) and Bölükbaş (29), $52.7 \%$ and $52.3 \%$ of nursing students chose the nursing profession willingly, respectively. If nursing learners willingly chose the profession and have positive attitudes toward the profession, then they can contribute to improve the nursing profession. It is thought that choosing the profession willingly and positive attitude toward the profession could contribute to the development of the nursing profession.

In our study, a statistically significant positive correlation was found between attitudes toward nursing profession and motivation. Similarly, the study of Korkmaz and Ipekçi (30) found that students who were satisfied with the nursing profession have higher internal, external, and occupational learning motivation scores. Considering that high motivation of students will be an important factor in creating and maintaining a positive education environment, it is important to allow students to choose the nursing profession voluntarily.

\section{CONCLUSION}

The findings in this study demonstrated that first-year students have more positive attitudes toward the nursing profession than other classes. It is thought that it will be beneficial to conduct further studies to determine the related factors that cause the decline of motivation of students who are in undergraduate nursing education over time. Female nursing students are still more likely to choose the nursing profession in Turkey, and negative motivations for choosing nursing include personal characteristics, such as being incompatible with their personal interests. To reduce the gap between the numbers of male and female students, male nurses could become positive role models by providing information to high school students about the work they do in the hospital.

The nursing profession is facing great staffing shortages, so nursing institutions must show apprentice nurses with positive attitudes toward the profession throughout nursing school. The findings of this study show that for fourth-year nursing students, both school and hospital administrators could help students better understand their future jobs by emphasizing motivation sources such as intrinsic and extrinsic motivations.

\section{Ethics}

Ethics Committee Approval: Ethical approval was obtained from the Non-Interventional Clinical Research Ethics Board of the University Health Sciences Turkey (18/322).

Informed Consent: After the participants were informed about the study, data were collected from those who agreed to participate. The study was conducted on a voluntary basis.

Peer-review: Externally peer-reviewed.

\section{Authorship Contributions}

Concept: D.S., E.G., M.E.E., Design: D.S., E.G., M.E.E., Data Collection or Processing: D.S., E.G., M.E.E., Analysis or Interpretation: D.S., E.G., Literature Search: D.S., E.G., M.E.E., Writing: D.S., E.G.

Conflict of Interest: No conflict of interest was declared by the authors.

Financial Disclosure: The authors declared that this study received no financial support

\section{REFERENCES}

1. Mimura C, Griffiths P, Norman I. What motivates people to enter professional nursing? J Adv Nurs 2012;68:1615-23.

2. Eley R, Eley D, Rogers-Clark C. Reasons for entering and leaving nursing: an Australian regional study. Australian J Adv Nurs 2009;28:6-13.

3. Jirwe M, Rudman A. Why choose a career in nursing? Journal of Adv Nurs 2012;68:1615-23.

4. Takase M, Maude P, Manias E. Impact of the perceived public image of nursing on nurses' work behaviour. J Adv Nurs 2006;53:333-43.

5. Kemmer LF, Paes da Silva MJ. Nurses' visibility according to the perceptions of the communication professionals. Rev Lat Am Enfermagem 2007;15:191-8.

6. Al Jarrah IAT. Associate nursing students' perceptions toward nursing profession in Jordaz. Eur Sci J 2013;9:147-63.

7. Čukljek S, Jureša V, Bile CG, Režek B. Changes in nursing students' attitudes towards nursing during undergraduate study. Acta Clin Croat 2017; 56:36-43.

8. Ten Hoeve Y, Castelein S, Jansen W, Jansen G, Roodbol P. Predicting factors of positive orientation and attitudes towards nursing: A quantitative cross-sectional study. Nurse Educ Today 2016;40:111-7.

9. Zencir G. Nursing students' attitudes towards the nursing profession, nursing preferred with the relationship between: example of Turkey. Dokuz Eylul University Faculty of Nursing E-Journal 2016;9:30-7.

10. Coban IG, Kasikci M. Development of the attitude scale for nursing profession. Int J Nurs Pract 2011;17:518-24.

11. Zysberg L, Berry DM. Gender and students' vocational choices in entering the field of nursing. Nurs Outlook 2005;53:193-8.

12. Onler E, Saracoglu G. Validity and Reliability of the Turkish Version of the HMSO. Dokuz Eylul Univ Nurse High Electron Journal 2010;3:78-85.

13. Acat M. B, Kosgeroglu N. Motivation's resources and problems scale. Anatol J Psychiatry 2006;7:204-10. 
14. Agarwala T. Factors influencing career choice of management students in India. Career Dev Int 2008;13:362-76.

15. Wu LT, Low MMJ, Tan KK, Lopez V, Liaw SY. Why not nursing? A systematic review of factors influencing career choice among healthcare students. Int Nurs Rev 2015;62:547-62.

16. Liu Y. Nurses' work role in the context of gender and Chinese culture: an online forum study. J Nurs Res 2010;18:117-25.

17. Grainger P, Bolan C. Perceptions of nursing as a career choice of students in the Baccalaureate nursing program. Nurse Educ Today 2006;26:3844.

18. Miers ME, Rickaby CE, Pollard KC. Career choices in health care: Is nursing a special case? A content analysis of survey data. Int J Nurs Stud 2007;44:1196-209.

19. Bregman G, Killen M. Adolescents' and young adults' reasoning about career choice and the role of parental influence. J Res Adolesc 1999;9:253-75

20. Law W, Arthur D. What factors influence Hong Kong school students in their choice of a career in nursing? Int J Nurs Stud 2003;40:23-32.

21. Jubas K, Knutson P. Seeing and be(liev)ing: How nursing and medical students understand representations of their professions. Studies in the Education of Adults 2012;44:1:85-100.

22. Sand-Jecklin KE, Schaffer AJ. Nursing students'perceptions of their chosen profession. Nurs Educ Perspect 2006;27:130-5.
23. Turgay AS, Karaca B, Çeber E, Hemşirelik GA-AÜ, 2005 U. The investigated of perceptions of nursing profession in nursing students. Journal of Atatürk University School of Nursing 2005;8:54-62.

24. Lou JH, Yu HY, Hsu HY, Dai HD. A study of role stress, organizational commitment and intention to quit among male nurses in southern Taiwan. J Nurs Res 2007;15:43-53.

25. Rajacich D, Kane D, Williston C, Cameron S. If they do call you a nurse, it is always a "male nurse": Experiences of men in the nursing profession. Nurs Forum 2013;48:71-80.

26. Bjorkstrom ME, Johansson IS, Hamrin EKF, Athlin EE. Swedish nursing students' attitudes to and awareness of research and development within nursing. J Adv Nurs 2003;41:393-402.

27. Hendel T, Kagan I. Professional image and intention to emigrate among Israeli nurses and nursing students. Nurse Educ Today 2011;31:259-62.

28. Guducu Tufekci F, Yildiz A. The students' reasons of nursing preference and ideas about their future. Journal of Ataturk University School Nurs 2009;12:31-7.

29. Bölükbaș N. Nursing students' choice of profession and influencing factors. Ordu University Journal of Nursing Studies 2018;1:10-7.

30. Korkmaz AÇ, Ipekçi NN. Motivation in nursing education: ıntrinsic and extrinsic motivation resources of students, J Health Nurs Manag 2015; 3:121-31. 